\title{
Causas de la erosión del tejido social en Chile
}

\author{
Jaime Abedrapo*
}

\section{RESUMEN}

Chile ha sido epicentro de un conflicto político y social que ha llevado consigo la expresión de violencia y que ha puesto en jaque a las instituciones de la República. En tal sentido, es relevante realizar una reflexión respecto a las causas de dicho fenómeno.

$\mathrm{Al}$ respecto, hemos escogido la erosión del tejido social como el elemento central de análisis que deja al descubierto el irrespeto entre los connacionales, los niveles de frustración de una parte de la población chilena, la falta de representación política de las demandas políticassociales y, sobre todo, la necesidad de replantearse la estructura política del país, y el diseño mismo de las políticas públicas en vista a reconstituir el tejido social desgarrado.

Palabras clave: democracia liberal, tejido social, gobernabilidad, comunidad y corrupción.

\section{Causes of Social Fracture in Chile}

\section{Abstract}

Chile has been the epicenter of a political and social conflict that has brought with it the expression of violence that has put the institutions of the Republic in trouble. In this sense, it seems relevant to reflect on the causes of this phenomenon.

In this regard, we have chosen the erosion of the social fabric as the central element of analysis that reveals the disrespect among compatriots, the levels of frustration on the part of the Chilean population, the lack of political representation of political-social demands and Above all, the need to rethink the country's political structure, and the design of public policies in order to reconstitute the torn social fabric.

Keywords: Liberal democracy, social fabric, governability, community and corruption.

\footnotetext{
Doctor en Derecho Internacional y Relaciones Internacionales por el Instituto Universitario Ortega y Gasset de la Universidad Autónoma de Madrid. Cientista político y periodista. Actualmente, es director de la Escuela de Gobierno de la Universidad San Sebastián (USS) de Chile. Correo electrónico: jaime.abedrapo@uss.cl

(iD) https://orcid.org/0000-0002-7555-1574
} 


\section{Introducción}

Luego del estallido social el 18 de octubre de 2019 se abrió un futuro incierto respecto al devenir de Chile, principalmente sobre cómo renovar la confianza en las instituciones de la república para generar las condiciones de una representación política efectiva. Tal vez sea el momento de replantearnos pasar de un régimen democrático de representación de corte liberal, que se sustenta en políticos profesionales, a un sistema de participación más directa en la toma de decisiones por parte de la ciudadanía.

En esa disquisición estábamos cuando emergió la pandemia del COVID-19, que enfrió la discusión política y social y modificó la agenda nacional, dando así un respiro a las autoridades que, en tiempos de catástrofe, retoman la conducción para enfrentar una crisis que amenaza la salud de la ciudadanía, aunque las interrogantes se mantienen. Pero, ¿luego de superada la crisis sanitaria, resurgirá la violencia en las calles? Esta es una interrogante especialmente relevante si proyectamos un contexto en que la economía estará sumergida en una profunda crisis debido al desempleo, la recesión, la quiebra de empresas pequeñas y medianas, y posiblemente de algunas grandes. Entonces, ¿̇cómo reaccionaremos los chilenos? Aún no lo sabemos, pero muy posiblemente el contexto será distinto después del aislamiento social al cual hemos tenido que someternos.

En un escenario de crispación en que han renacido profundas demandas sociales y políticas, podemos afirmar que habría al menos un par de asuntos complejos a visualizar en el período pospandemia, relativos al real impacto que tendría una mayor participación política. El primero guarda relación con una mayor participación en las decisiones a nivel de territorio local, en el ámbito sectorial y también nacional mediante consultas directas a los electores; $y$, el segundo, con la necesidad de verificar que la ciudadanía se haga responsable de las decisiones que adopta de manera mayoritaria.

En efecto, la mal evaluada clase política actual sirve de pretexto para asignarles la responsabilidad de todos los males denunciados por la ciudadanía, mientras esta se moviliza y toma una actitud de demanda en torno a sus intereses. Además, la ciudadanía no necesariamente propone respuestas desde una mirada integral u holística con visión de bien común, lo que denotaría una pérdida de sentido común que ha sido reemplazado por una conflictividad y crispación social ascendente, producto de una frustración y percepción de abuso generalizado por parte del sistema político. Ahora, si bien esta percepción tiene muy buenas razones para la decepción, llama la atención cómo, hasta el momento, no se presentan alternativas para la representación social y política. ¿Nadie quiere hacerse responsable de la conducción política? ¿Nadie 
quiere convertirse en político profesional? ¿Nadie quiere velar por algo más que un interés en específico o el sector en el cual participa?

Luego de la crisis por el coronavirus, ha quedado de manifiesto la debilidad de las democracias en general para abordar la emergencia. A su vez, los populismos han quedado al desnudo en su ineptitud ante situaciones en que se requiere responsabilidad en la conducción de las políticas de emergencia. En tal sentido, frente a un escenario de inseguridad, se podría esperar un cierto cambio en la percepción del mundo por parte de los ciudadanos de las democracias liberales.

Por otro lado, el miedo tampoco suele ser buen consejero, ya que en período de catástrofes hay una tentación de controlar a las poblaciones más allá del régimen de excepción. Por ello, más que una reivindicación de la seguridad en su sentido lato. que resulta necesario en tiempos de pandemia, se requiere explicitar el tránsito desde esta protección y seguridad hacia una nueva legitimidad del pacto social, cuestión que no se funda en el miedo, sino en la liberación que trae consigo la cohesión social, la unidad nacional, y que pareciera que solo surgirá desde las trasformaciones de la estructura política del país. Es decir, no desde la violencia sino desde el encuentro. En definitiva, es un asunto primordialmente de actitud y disposición, cuestión que hasta hoy se percibe muy difícil en Chile.

Desde otra perspectiva, la crisis política actual sobrepasa a la capacidad de respuesta de los paradigmas modernos del régimen de representación fundado en la democracia liberal, ya que — siguiendo la tendencia mundial—, en Chile también se ha cuestionado en su forma y fondo. ¿Por qué? Básicamente porque se percibe como anacrónico frente al proceso de digitalización y big data actual. Estas nuevas tecnologías permitirían una mayor participación e inclusión ciudadana sin mediación de políticos profesionales que, además, se les asocian con el aumento de la concentración de capital global producto del sistema financiero y comercial instaurado o impuesto a nivel mundial. Esta situación se percibe como verosímil por parte importante de los chilenos, por lo que la consecuencia sería que las personas estarían supeditadas a las necesidades del capital y grandes operadores financieros.

En Chile, se ha denominado a esto como la sensación permanente de abuso de los ciudadanos por parte de actores relevantes de la economía: desde los fondos de pensiones con sus rentas anuales millonarias, las colusiones de precio de grandes empresas alimentarias, el aumento unilateral que los seguros de salud realizan a sus clientes, hasta el pago de las concesionarias que suben discrecionalmente el pago por el uso de las autopistas; estas entre muchas más circunstancias en que los ciudadanos se sienten a merced de políticas arbitrarias que no cuentan con una regulación pertinente por parte del Estado. 
En tal sentido, el presente artículo busca respuestas a la violencia social y política registrada en Chile desde dos dimensiones diferentes, pero complementarias. Una primera examina las tendencias plasmadas en las directrices de la economía mundial a través del liberalismo económico, sus contradicciones y consecuencias en la cohesión social en las sociedades.

Desde una segunda dimensión, se intenta observar y analizar sobre qué ethos cultural se siembran (o imponen) dichas directrices que tienden a homogeneizar el pensamiento contemporáneo, las estructuras y diseños de las políticas globales en el ámbito comercial, financiero y crediticio, las cuales han sido aprendidas e implementadas en Chile a partir de su inicio republicano, habiéndose revitalizado en la Constitución de 1980. Al respecto, parece relevante describir las raíces culturales sobre las cuales se han implementado las políticas de desarrollo de la nación y cuáles han sido algunas de sus consecuencias, sobre todo en un contexto en que el mundo político ha presentado como una alternativa para la salida a la actual crisis del país, un debate constitucional.

Dicho esto, en el ámbito de las hipótesis vemos que la irrupción de la violencia estuvo precedida de varios elementos de análisis que tienen un común denominador: la pulverización del tejido social, fundamentalmente a raíz de un deterioro de la visión de vida en común por parte de la población residente en Chile. Con ello, la causa primera estaría en el individualismo, el cual ha caracterizado el diseño de las políticas públicas en un contexto general de pérdida de sentido de pertenencia de los miembros del pueblo.

$\mathrm{Al}$ respecto, y como botón de muestra, vemos como las encuestas revelan que una gran mayoría de los chilenos, sobre el 70\%, apoya el sistema de capitalización individual y mira con desconfianza cualquier diseño en materia de pensiones que vaya en dirección del principio de solidaridad. Ese raciocinio mayoritario no se construyó sobre la nada, sino en los propios cimientos de nuestra sociedad posdictadura (1973-1990).

Desde el retorno a la democracia en Chile se ha mantenido una cierta desconfianza al Estado y/o sector público, que con razón o sin ella, inclina la toma de decisiones del sector privado y público hacia conductas de resguardo del individuo y sus intereses. En este sentido, se nos presentan las primeras interrogantes que nos acercan a las razones de la pulverización de nuestra cohesión social: ¿para qué vivimos en sociedad?, ¿nos debemos los unos a los otros?, ¿la mejor manera de que prevalezca el bien común es en el marco de racionalidad eximente del interés o afecto por el otro?

Las interrogantes hasta hace poco, en términos generales, eran respondidas desde las políticas macroeconómicas que nos han presentado como el país más exitoso de América Latina en materia de crecimiento y disminución de la pobreza, y con una proyección —según varios rankings - que le permitiría alcanzar los niveles de los 
países desarrollados (OCDE, 2018) ${ }^{1}$. Sin embargo, las razones netamente materiales e inmanentes no fueron capaces de evitar la decepción y frustración en materia de expectativas, ya que precisamente la falta de afecto y el desinterés por crear comunidad fueron atomizando a la sociedad y levantando reivindicaciones ajustadas a intereses particulares (Abedrapo, 2012). Esto tampoco, per se, nos da respuestas para la construcción de sociedad, sino que precisamente nos aproxima a una mayor conflictividad social destructiva, al menos, en el corto plazo.

\section{El individualismo}

Los globalizadores o defensores del régimen internacional de comercio están perplejos con la irracionalidad desatada desde el 18 de octubre en Chile, principalmente a manos de ideologías que parecían vencidas. Sus argumentos en favor del sistema vigente en Chile parecen serios, se sustentan básicamente en las tasas de crecimiento del producto interno bruto en las últimas cuatro décadas del país y en la baja constante de personas que viven en la pobreza. Por lo tanto, el problema de orden público debiera atenderse a la brevedad, de modo de no interrumpir la senda de progreso que llevaba el país. Desde esa perspectiva, la razón de la violencia registrada se sustenta únicamente en tesis conspirativas y ataques a la democracia por parte de admiradores de ideologías marxistas, anarquistas o seguidores del chavismo.

Desde esta mirada, la concepción de comunidad parece inexistente y el relativismo se instala en materia económica y justicia distributiva, puesto que el sistema vigente afirma que la "ciencia» economía es amoral, transformando el mercado en el baluarte de la racionalidad y de los "valores» que en sí sabrán recompensar a los actores económicos de manera justa y racional (Rawls, 1986). Empero, los axiomas señalados no son sostenibles, ya que se desvinculan de la valoración de los actos humanos. Desde otra perspectiva, el mercado en Chile hace mucho tiempo muestra evidencia de su precariedad a través de la colusión, los oligopolios y otras características de nuestra sociedad que no permiten la igualdad de oportunidades en el mercado, evidenciando una frágil regulación por parte del Estado, trasformando al mercado competitivo más en un espejismo que en una realidad. Todo esto frente a una comunidad que se siente amenazada y desvalida frente a los operadores económicos (Abedrapo, 2019b).

En otra perspectiva, apreciamos cómo en los tiempos de individualismo, la propiedad se ha trasformado en neurálgica para entablar los cimientos de un orden de respeto de los «derechos humanos», limitando el concepto de persona en su exacta dimensión,

\footnotetext{
1 Chile ocupaba el puesto 38 a nivel mundial y se proyectaba como el país más desarrollado de Latinoamérica, estando a las puertas del desarrollo (Vergara, 31 de enero de 2019).
} 
ya que se sostiene que el fin inmediato, en la lógica de Hayek y Shumpeter, es satisfacer a las futuras necesidades que aún se desconocen, dando así el argumento a favor de la acumulación, siendo esta la realidad que causa la insostenibilidad medioambiental y mala distribución de los ingresos. En Chile - como un buen ejemplo de país que ha escogido el desarrollo sustentado en la exportación de materias primas y/o recursos naturales - el desarrollo económico se ha concebido con externalidades negativas justificadas sobre el medio ambiente social y ecológico, ya que primero se debe capitalizar, para posteriormente preocuparse por esas variables consideradas como secundarias. Ahí podría estar el origen principal del estallido social, dado que una parte de la población se ha frustrado en la espera del denominado «chorreo» económico que no llega.

En efecto, Chile tiene el desafío de modificar — trasformar- sus lineamientos económicos estructurales, los cuales hoy en día se conciben como los condicionantes de un desarrollo insostenible en lo social y en lo ecológico.

El cambio posiblemente deba presentar una hoja de ruta gradual, pero decidida para la reconversión del país. Posiblemente, Chile deberá alcanzar acuerdos políticos y sociales para modificar las garantías a la acumulación de capital y/o patrimonio por sobre cualquier otra consideración (Sen, 1998). Desde esa perspectiva, se requerirá el retorno de la política y el distanciamiento de los administradores del Estado, que más o menos siguen anclados al paradigma modernista de crecimiento insostenible.

En definitiva, es una cuestión de concepción de libertad. Actualmente, esta es netamente material, inmanente, sin capacidad de obligarse para con los demás y, por ello, incapaz de reconocer a la sociedad como un objetivo político trascendente, en cuanto a que la realización personal no es mediante ella, sino en ella. Ello resulta evidente cuando no se requiere estudiar el pensamiento político y económico de los ministros de Hacienda en el pasado reciente para comprender la lógica que impera tras la concepción de libertad en el diseño y ejecución de las políticas públicas en Chile. Basta con comprender a pensadores liberales como John Rawls (1986, p. 83), que nos brinda elementos con que observar, desde el liberalismo y el pensamiento utilitarista, los alcances de la visión de justicia social y los derechos individuales que protegen en primera dimensión, entre otros, a la propiedad privada.

En datos, Chile ha seguido estrechamente la senda del desarrollo de corte liberal y con gran apertura económica hacia los mercados internacionales, lo que ha derivado en que un 33\% del ingreso se concentre tan solo en el $1 \%$ más rico de la población; pero además de esta concentración, la elevada desigualdad de ingresos tiene una segunda característica que es la gran cantidad de trabajadores con salarios bajos (PNUD, 2017, pp. 22 y 23). En tal sentido cabe preguntarse, ¿será un resentido social quien advierta que ello no es un crecimiento sano ni justo para el país? 
Rawls argumentó que una sociedad efectivamente regulada por la concepción pública de la justicia, está concebida sobre los siguientes criterios: todo el mundo acepta y sabe que los otros aceptan los principios de la justicia; las instituciones sociales básicas se articulan en un esquema para satisfacer esos principios; la concepción pública de justicia está fundada en creencias razonables establecidas por métodos de investigación generalmente aceptados; cada uno de los miembros de la sociedad bien ordenada observa un sentido de justicia que normalmente es efectivo; cada miembro percibe metas e intereses fundamentales legítimos tras el quehacer de la institucionalidad; cada miembro tiene derecho a un igual respeto y consideración a la hora de determinar los principios por los cuales ha de regularse la estructura básica de su sociedad; las instituciones sociales básicas generan un sentido de la justicia efectivo; existen condiciones moderadas de escasez; hay una diversidad de intereses y fines fundamentales; existen instituciones básicas autosuficientes por la cooperación social para el bien mutuo; los principios de justicia especifican cómo las instituciones pueden influir en la distribución global de beneficios; y que los miembros consideran la estructura básica de la sociedad como objeto primario de la justicia (Elster, 1997).

Así, Rawls estableció criterios para determinar la relación entre los bienes primarios de la sociedad y los que surgen por consenso y no por necesidad. Establece que cada persona tiene igual derecho al más amplio esquema de libertades básicas compatible con un sistema de libertades para todos (PNUD, 2017, p. 60).

Un segundo criterio de dicho autor es que la justicia debiera reparar las desigualdades económicas y sociales, debiendo satisfacer a los miembros menos favorecidos de la sociedad mediante mecanismos que deben estar abiertos a todos en igualdad de oportunidades. En otras palabras, la escasez es un concepto relativo y la noción de justicia es inexistente, ya que solo se concretan acuerdos o consensos que establecen mínimos comunes denominadores, y mientras no se plasman en derechos son inexistentes.

Así el individualismo actual encuentra en la focalización de los recursos la acción más eficiente para combatir la pobreza y la escasez, sin establecer criterios para una sociedad justa; entendiendo que la libre acción de los individuos solo encontraría límites en la autorregulación.

Ello ha dado como resultado que la amistad cívica se desdibuje y el individuo se mantenga bajo relaciones sociales de carácter utilitario y no sobre la necesaria justicia social tras un objetivo comunitario o fin social común (Abedrapo, 2019b). 


\section{Democracia liberal y la insatisfacción de la representatividad}

La encuesta de Latinobarómetro nos ha revelado un aumento de la decepción de los ciudadanos con el funcionamiento de la democracia. Para el informe de 2018, la insatisfacción de la democracia en Latinoamérica pasó de un $51 \%$ a un $71 \%$ (Latinobarómetro, 2018).

Al respecto, podríamos suponer que las instituciones están siendo mal valoradas por su desfase con las nuevas tecnologías, considerándolas anacrónicas a la realidad virtual de estos días. Por ello, la ciudadanía exigiría mayor participación y resultados por parte de las políticas públicas que emanan desde las instituciones. Sin embargo, esta explicación se nos muestra superficial, ya que la misma modernidad ha condicionado a los individuos hacia el pragmatismo, vacío espiritual y el individualismo, características que conllevan la insatisfacción y falta de sentido social, el cual intenta ser reemplazado por el individuo asociado a aspiraciones de prestaciones, servicios y bienes infinitos al margen de un contexto en sociedad.

A inicios de 2019, el expresidente Ricardo Lagos señaló que las expectativas frustradas de una mejor calidad de vida eran justamente una de las razones de la existente decepción de la democracia representativa y añadió que «tanto en Latinoamérica como en otros lugares como Europa y Estados Unidos la tendencia es a que los sectores medios se sientan defraudados, generando ello una frustración entre los ciudadanos que se ha ido incrementando a escala mundial» (CEPAL, 26 de noviembre de 2018).

A ello podemos señalar una precisión, y es que el individuo insatisfecho está relacionado primeramente con la precariedad espiritual y no tanto con el crecimiento del $\mathrm{PMG}^{2}$, ya que la racionalidad moderna dio autonomía ilimitada a los individuos, truncó la moral y transformó a las personas en clientes de bienes y servicios, perdiendo la noción de bien común y república. En general, al hombre moderno le cuesta comprender la dimensión espiritual, social y afectiva como sustento de la comunidad que da sentido a la vida, y de paso nos abre el camino a la realidad del crecimiento consciente, como sinónimo de sostenible. En este punto, el hombre aún anclado al ethos de la modernidad prefiere apostar únicamente por las nuevas tecnologías, pues así evita el compromiso con el medioambiente y con los demás.

La corriente liberal ha conseguido instaurar el concepto de progreso individual como un bien en sí mismo y la sociedad como una oportunidad para conseguir mis deseos o preservar mis intereses, ante lo cual el Estado debe ser un árbitro justo en la creación de las reglas del juego. Ello parte desde los operadores multinacionales o trasna-

\footnotetext{
2 http://www.sag.cl/quienes-somos/programa-de-mejoramiento-de-la-gestion-pmg\#:--text=Es\%20un\%20 instrumento\%20de\%20apoyo,Recursos\%20Humanos
} 
cionales, ampliándose a una cosmovisión del individuo medio, cuestión que está en el epicentro de nuestra insostenibilidad actual.

En este sentido, se pueden otorgar datos objetivos de una población que hoy goza de más y mejores libertades políticas que ayer, además de un mayor ingreso per cápita, entre otros indicadores. Sin que por ello se sienta más satisfecho o integrado en la sociedad, ya que hablamos de «mercado» más que de «comunidad».

Muy posiblemente el malestar ciudadano tiene que ver más con el hombre y mujer moderno o posmoderno que con una perspectiva de performance institucional.

En perspectiva, pareciera una obviedad que las instituciones latinoamericanas en general y la chilena en particular no están funcionando adecuadamente según lo permiten hoy las tecnologías, sobre todo abriendo espacios a una mayor participación ciudadana y el desafío de la big data. Sin embargo, ¿̇erá esa la respuesta de fondo a la desafección ciudadana? Pareciera que no, según lo que hemos reflexionando hasta ahora.

De otro lado, la desvalorización de la democracia en Chile va de la mano con los escándalos de corrupción de políticos y autoridades de las instituciones públicas. Desde el mismo ejemplo señalado anteriormente, que aproximadamente el 60\% de los cotizantes — según estudio de opinión de la UDD (2020) — quiere que el aumento en materia de pensiones vaya a su cuenta individual y no al pilar solidario, es un dato relevante al momento de entender las consecuencias del individualismo en nuestros días (Universidad del Desarrollo, enero de 2020), y comprender cuál es el juicio que los ciudadanos tienen de los organismos públicos. Si ello no se modifica, no habría posibilidades de trasformaciones hacia una mayor cohesión social.

En consecuencia, nuestras poblaciones tienden a vincular sus intereses a derechos exigibles cada vez más difíciles de garantizar por el Estado, mientras que a su vez no se sienten responsables de la nación, ni menos comprenden o adhieren una visión de bien común. Este pareciera ser el real escollo para salir de la crisis política por la que atraviesa Chile.

Las preguntas que parecen surgir para intentar ponderar el ethos cultural predominante son: ¿será el hombre utilitarista el idóneo para la defensa de la democracia representativa?, y ¿alguien podrá intentar ejercer autoridad para velar por el bien común, en un contexto en que prima la política como una suma de intereses individuales? En el siguiente apartado intentaremos comprobar la hipótesis acerca de las causas de la enfermedad de la democracia en Chile desde la conformación de la nación, en donde también encontraremos elementos que explican el estallido social. 


\section{Latinoamérica y Chile desde sus raíces}

Fijémonos primeramente en la política en Latinoamérica, la cual pareciera carecer de pacto social y de identidad, ya que esta región ha perdido sentido de pertenencia desde los tiempos de la ilustración, la influencia masónica y el cambio de orden mundial, lo que tuvo un impacto en manifestaciones a nivel social, económico y cultural.

Ese proceso desdibujó el papel del indigenismo y del cristianismo, robusteciendo la «idea de progreso» como un camino que debía superar dichos estadios, pues de otro modo estaríamos determinados a ser Estados subdesarrollados. En esta idea, Michael Reid (2009, pp. 32-35) fundamenta el proceso que va desde la esperanza a la desilusión para el continente Latinoamericano, en relación con el proyecto político y económico, defendiendo que la constante en la región ha sido la frustración. Ciertamente, el autor explica que las razones son varias, pero fundamentalmente no saber cómo implementar las políticas liberales.

En efecto, tras la derrota de la visión de Bolívar para Latinoamérica, primó la tendencia liberal, es decir, la mirada crítica a las tradiciones, y en su reemplazo se impuso la noción de libre comercio como sinónimo de un nuevo eje de desarrollo que apuntó a la aceleración de la extracción de materias primas para apoyar el proceso de industrialización que vivían algunas potencias europeas, en particular Inglaterra (Carriquiry, 2017).

En dicho contexto, la apuesta fue a la «especialización» de los Estados nacionales, organizaciones políticas que vivían sus procesos de autonomía de España pero que a su vez fueron quedando huérfanos de identidad y propósito político común en Latinoamérica.

Por otro lado, hacia el interior de la comunidad se produjeron grietas sociales existentes hasta hoy en América Latina, ya que entre las elites criollas se evidenció el sentimiento de vergüenza a su pasado indígena «irracional y/o primitivo», mientras que el legado e identidad católica se le asimiló como un lastre de oscuridad que mantuvo lejos a Latinoamérica del progreso y el desarrollo del Estado-Nación. Por lo tanto, en varios países la división Estado-Iglesia tuvo el objeto de laicizar la sociedad, empujándolas hacia un pseudocientificismo.

Así, la convocatoria de Bolívar a impulsar una confederación de los pueblos liberados del dominio espańol quedó como una visión romántica e idealista, puesto que cada nación emergente intentó adaptarse desde el interés de sus nuevas clases gobernantes a las necesidades de un mundo interdependiente o, mejor dicho, dependiente de los nuevos capitales extranjeros, como medio más «eficiente» de racionalizar el sistema 
político y económico. Así se inició un proceso que tendió a homogeneizar las políticas hacia los indígenas, sin considerar que «los indios no eran un grupo homogéneo, [que] pertenecían a diferentes etnias, con sus propias lenguas, costumbres y tradiciones religiosas [...]. Carecían de una identidad común» (Carriquiry, 2017). Solo a los ojos del conquistador y colonizador estos grupos humanos tenían características comunes, y por ello crea el concepto de «indio» con el objeto de diferenciarlo de los españoles, negros, mestizos y criollos. Esta situación de una incomprensión de los colonos respecto de la identidad de los pueblos originarios se acentuó con el cambio de gobernantes en Latinoamérica, quienes bregaron por ser independientes, cuestión que determinó que la razón de Estado fuera la creación de una nacionalidad homogénea al interior de sus fronteras (Abedrapo, 2019a).

Al respecto, Margarita Favela Gavia y Diana Guillén (2009, pp. 22-23) sostienen que la democracia liberal como forma legítima de Estado (luego de las transiciones a la democracia), se caracterizó por crear un contexto jurídico, ideológico y legal a partir de lo cual han surgido actores sociales que anteponen el derecho de la ciudadanía, como una manera trascendente de cambiar las imposiciones de las elites.

Como consecuencia de lo señalado, en Latinoamérica se registran Estados frágiles en lo político, social y económico, primeramente, porque la población indígena es perseguida y, en general, reconocida como un obstáculo al desarrollo y conformación de la identidad nacional, una que debía crearse a imagen y semejanza de la Europa industrializada de aquel entonces, y que nuevamente adquiere bríos tras la ola liberal de los ochenta y noventa en el sistema internacional, tras la caída del muro de Berlín y la descomposición de la URSS.

En los hechos, Chile ha sido un buen ejemplo al respecto, situación que ha sido una de las causas de la fractura social que hoy tenemos con nuestros pueblos originarios y que, desde la década de los noventa del siglo XX, en pleno proceso de transición a la democracia, ha gatillado actos de violencia política que hasta hoy no han cesado.

El ideal de ciudadano en países como Chile, mirado desde la elite, ha conseguido desarraigar la identidad y carácter de la sociedad conformada durante la colonia. De hecho, en términos generales las políticas nacionales despreciaron las lenguas y dialectos de los pueblos originarios, intentaron reformar la organización societal según los criterios de la ideología liberal expresada en la burguesía, por tanto, cambiaron la relación con la naturaleza debido a la mirada utilitarista imperante en la época inspirada por Francis Bacon, entre otros, y nuevamente reimpulsada por autores como Milton Friedman desde la década de 1980, fundadores de la escuela de Chicago, que han influido hasta hoy en el diseño de las políticas públicas de Chile. Recordemos que los principios de Williamson durante la década de 1980 se resumen 
en tres elementos principales (Reid, 2009, p. 202). El primero busca la estabilidad macroeconómica (para así dominar la inflación); el segundo ha sido desmantelar el proteccionismo y abrir el comercio exterior, en favor de atraer inversión privada extranjera; y el tercero impulsa la competencia como el gran objetivo del mercado y así generar riqueza sin importar el impacto en la cohesión social y ecológica.

Las consecuencias sociales para los Estados en conformación desde la impronta liberal de inicios del siglo XIX son desgarradoras, básicamente por la pérdida de respeto y tolerancia entre los distintos actores políticos y sociales, cuestión que perdurará por casi un siglo sin mayores correcciones hasta el surgimiento del fenómeno político conocido como la "cuestión social» en América Latina, en el cual los indígenas y asalariados inician un camino de identificación de clase y posteriormente una lucha por la dignidad de su identidad. Así entendemos la causa eficiente del maltrato físico y psicológico otorgado a los pueblos originarios y el mal trato recibido por los obreros.

El sistema relegó a las personas a ser un mero instrumento de desarrollo del capital. Todo ello a poco de iniciar las vidas independientes de los Estados Latinoamericanos. Esta situación en Chile se mitigó durante el siglo XX, sin embargo, la política de sustitución de exportaciones llevó al país a una gran inestabilidad fruto de tasas de inflación altísimas (en la década de los setenta, superó el 1.000\%) y la frustración de no conseguir industrializar su sociedad, manteniendo una dependencia con potencias extrarregionales.

Dicha situación nuevamente dará espacio a la búsqueda de respuestas sociales por medio de la ideología liberal que permitió el crecimiento macroeconómico del país (cuadruplicando su PIB desde mediados de la década de 1980 al 2000), pero a costa de la pérdida de percepción de pertenencia a una misma comunidad. Al respecto, cabe observar cómo antes del proceso independentista los indígenas:

[...] tenían un estatuto jurídico y social [...]. Eran hombres y mujeres que en las actas de bautismo estaban registrados como indígenas; vivían en los pueblos de indios y respetaban sus usos y costumbres; gozaban de privilegios como el derecho a tener tierras comunales, entre ellas el fundo legal que comprendía 600 varas a partir del centro del pueblo (aproximadamente $101 \mathrm{ha}$.), y tienen obligaciones como pagar tributos a la corona espańola y cumplir con los cargos comunales. (Von Wobeser, 2011)

Ciertamente un orden bastante lejano de ser justo a los ojos del comunitarismo o personalismo, pero bastante más respetuoso que el que se impondrá a través de las políticas nacionales en los tiempos de construcción de la nacionalidad chilena, que hasta hoy no los reconoce explícitamente como pueblo.

La reacción en contra de esta institucionalidad fue una muestra manifiesta del proceso de racionalización fundado en la idea de progreso, la que desconoció la estructura 
social de América Latina, empujando a vastos sectores de la población a quedar al margen del desarrollo, sumidos en la extrema miseria y en la exclusión política y social respecto a su identidad y dignidad. En esta perspectiva, el proceso que proviene desde la «independencia» dejó las bases para la inestabilidad política. En palabras de Julio Bazán (2011):

[...] la situación actual en la Araucanía no es, evidentemente, un fenómeno social que surgiera de pronto en 1998 (refiriéndose al período de transición de la democracia tras la dictadura). Sus raíces, el desarrollo de la relación entre los naturales de estas tierras y el conquistador primero y los hispanos chilenos luego, el mestizaje generalizado [...]. Son las causas de la situación actual (que no hemos sabido abordar). (p. 115)

Es decir, es un asunto estructural en la conformación del hombre moderno, en consecuencia, viene desde antes y durante la conformación del Estado chileno.

Esta sensación de sentirse al margen del desarrollo social ha sido una constante en Chile durante el siglo XX. Así tenemos el ruido de sables de fines de la década de 1920 que acusaba a las elites políticas y empresariales de indiferencia ante la situación social de los chilenos, la rebelión de la chaucha en la década de 1950 — motivada por la pobreza y la impotencia de la población ante el aumento del precio de suministros básicos—, el golpe de Estado en la década de 1970 — que catalizó la desintegración societal e ideologización que exhibía la sociedad chilena desde la década de 1960—, y el actual estallido social que ha vivido el país. Esto ha sido decisivo al momento de comprender el estallido de violencia del que hemos sido testigos desde el 18 de octubre de 2019, hasta la emergencia del coronavirus que surge en Chile en marzo de 2020 .

En consecuencia, el proceso de descomposición social e identitario tiene su causa más profunda tras la crisis de la cristiandad por parte de las elites emergentes desde mediados del siglo XIX. El país extravió sus raíces y el interés por los costos sociales del crecimiento.

Dicho proceso se daría con dureza en un contexto de vacío de sentido y visión de futuro respecto al desarrollo político e institucional de la nación, lo que hoy apreciamos como la causa material de las violaciones a los derechos humanos registradas en dicho período, y que hasta hoy es el telón de fondo en la violencia callejera y en la ilegitimidad que los ciudadanos denuncian en contra de las instituciones de la república, y en los actos de abuso y corrupción que observan de la elite políticainstitucional, social, empresarial y eclesiástica. Así, estas habrían perdido la visión de sociedad y sucumbido frente al paradigma moderno caracterizado por el materialismo, inmanentismo y autonomía irresponsable del individuo. 


\section{Conclusiones}

Actualmente vivimos tiempos de confusión en materia política y antropológica, y las nuevas tecnologías que aceleran la interacción hasta llevarla a tiempo real a nivel planetario, nos presentan un nuevo desafío: insistir en que será el progreso tecnológico el que nos dará respuestas a nuestras frágiles comunidades.

La comunión sin liderazgos políticos y sociales que nos inviten a un futuro común centrado en la persona humana, capaces de conducir a los pueblos hacia el bien común y la fraternidad, será una reedición del extravío de nuestra sociedad. Caer nuevamente en la tentación de homogeneizarnos según criterios funcionales y globales reproducirá más las diferencias sociales y atomizará aún más la comunidad. Por ello, la urgencia en la búsqueda de identidad se nos presenta como imperiosa.

Además, Chile no presenta una visión de futuro. Seguimos anclados en conflictos sociales que nos amenazan con una agenda de seguridad nacional más que con una de integración y cooperación. Las causas son la carencia de liderazgo político y, más precisamente, los conflictos históricos heredados desde nuestra forzada independencia, proceso que no contempló reconocer nuestra identidad y futuro común. A ello se suma el ideario de la Constitución de 1980, desde el cual el país empalmó con una visión del mundo utilitarista de apertura económica, sin resguardo de la cohesión social.

En definitiva, no nos hemos adaptado a las transformaciones que nos plantea el cambio de época al cual asistimos, ya que es difícil que un sujeto que no sabe de sí mismo sepa hacia dónde se dirige, en especial en un contexto social atomizado y con claros rasgos de egoísmo, lo cual es sinónimo de un vacío espiritual.

Los números macroeconómicos se presentaban en una tendencia general positiva hasta el 18 de octubre de 2019, pero luego del estallido de violencia, este ha traído consigo un mar de incertidumbres y cuestionamientos a la institucionalidad del país, generando una situación de crisis política y social sin comparación desde el retorno a la democracia. Por ello, luego de superar la crisis sanitaria del COVID-19, el país seguirá requiriendo un reencuentro que guie la trasformación desde lo individual y superficial hacia la conciencia por crear comunidad.

\section{Referencias bibliográficas}

Abedrapo, J. (2012). Razones de una indignación. Personal. Revista Iberoamericana de Personalismo Comunitario, 8(19), 49-58. Recuperado de https://issuu.com/pdcdigital/ docs/persona-numero-19

Abedrapo, Jaime. (2019a). Conciencia latinoamericana. Recuperado de https://liderescatolicos.cl/postdiplomado/ensayos/JaimeAbedrapoEnsayo2.pdf 
Abedrapo, J. (2019b). Liberalismo económico o personalismo. Una mirada desde Chile. Revista de Derecho, Ciencias Sociales y Politicas, 25, 149-170. Recuperado de https:// revistaschilenas.uchile.cl/handle/2250/122729

Bazán, J. (2011). ¿Es mapuche el conflicto? Santiago de Chile: Editorial Maye.

Carriquiry, G. (2017). Memoria, coraje y esperanza. A la Luz del Bicentenario de la Independencia de América Latina. Granada: Editorial Nuevoinicio.

CEPAL. (26 de noviembre de 2018). Conferencia El estado de la democracia en América Latina. 40 años desde la Tercera Ola de la Democracia. Recuperado de www.cepal.org

Elster, J. (1997). Egonomics, análisis de la interacción entre racionalidad, emoción, preferencias y normas sociales en la economía de la acción individual y sus desviaciones. Barcelona: Gedisa.

Favela, M. y Guillén, D. (2009). Lucha social y derechos ciudadanos en América Latina. En M. Favela y D. Guillén (eds.), América Latina: los derechos y las prácticas ciudadanas a la luz de los movimientos populares (pp. 21-49). Buenos Aires: Consejo Latinoamericano de Ciencias Sociales - Clacso.

Latinobarómetro. (2018). Informe 2018. Base de Datos en Linea. Recuperado de http://www. latinobarometro.org/latdocs/INFORME_2018_LATINOBAROMETRO.pdf.

OCDE. (2018). Estudios Económicos de la OCDE. Recuperado de http://www.oecd.org/ economy/surveys/Chile-2018-OECD-economic-sruvey-Spanish.pdf

PNUD. (2017). Desiguales. Orígenes, cambios y desafíos de la brecha social en Chile. Santiago de Chile: Programa de Naciones Unidas para el Desarrollo. Recuperado de http://www.fundacionmicrofinanzasbbva.org/revistaprogreso/ desiguales-origenes-cambios-y-desafios-de-la-brecha-social-en-chile/

Rawls, J. (1986). Justicia con equidad. Material para una teoría de la justicia. Madrid: Tecnos.

Reid, M. (2009). El continente olvidado. La lucha por el alma de América Latina. Bogotá: Grupo Norma.

Sen, A. (1998). On Ethics \& Economics. Oxford: Basil Blackwell Ltd. Universidad del Desarrollo. (Enero de 2020). Estudio de Opinión Pública. Recuperado de www. gobierno.cl

Vergara, A. (31 de enero de 2019). Chile: a 5 años de ser un país desarrollado. Estadodiario.com. Recuperado de https://estadodiario.com/noticias/ chile-a-5-anos-de-ser-un-pais-desarrollado/

Von Wobeser, G. (2011). Los indígenas y el Movimiento de Independencia. Estudios de Cultura Náhuatl, 42, 299-312. Recuperado de http://www.journals.unam.mx/index. php/ecn/article/view/26564/24901

Recibido: 30 de marzo de 2020

Aprobado: 1 de setiembre de 2020 